\title{
Relationship between Swallowing Function, Diet Level and Pulmonary Function in Post-Stroke Patients
}

\author{
Myungeun Yoo, M.D., Hyo Jeong Lee, M.D., Eu Jeong Ko, M.D., Jinyoung Park, M.D., \\ Yoon Ghil Park, M.D., Ph.D.
}

Department of Rehabilitation Medicine, Gangnam Severance Hospital, Rehabilitation Institute of Neuromuscular Disease, Yonsei University College of Medicine, Seoul, Korea

\begin{abstract}
Objective: To identify the relationship between dysphagia, dietary level, and pulmonary function in post-stroke patients. Methods: Thirty-six post-stroke patients with dysphagia, who were hospitalized from June 2017 to October 2017 in the Department of Rehabilitation Medicine at a tertiary hospital, were analyzed retrospectively. The video-fluoroscopic swallowing study (VFSS) and videofluoroscopic dysphagia scale (VDS) were used to assess dysphagia. The vital capacity (VC) and peak cough flow (PCF) were used to assess the pulmonary function. Upon admission, the patients were divided into three groups according to their dietary level (tube feeding, dysphagia diet, and general diet). The correlation between dysphagia and pulmonary function was analyzed using an independent t-test test with the optimal points, and the relationship between the diet level and pulmonary function was evaluated using a one-way analysis of the variance.

Results: Significant correlations between the pulmonary function and sub-items of VDS were found in "oral transit time" with VC, "vallecullar residue" and "aspiration" with PCF, and "triggering of pharyngeal swallow", "VDS total score" with VC and PCF. The dietary levels upon admission had a significant correlation with VC and PCF. The VC among groups divided according to three diet levels showed statistically significant differences.

Conclusion: This study revealed the relationship between the pulmonary function and dysphagia in post-stroke patients. Moreover, the pulmonary function correlated with dietary level, even though it was not confirmed that it affected dietary levels. The clinical importance of the pulmonary function in post-stroke patients with dysphagia should be emphasized. In addition, a large-scale study is needed to determine the correlation between the pulmonary function and swallowing difficulty. (JKDS 2021;11:25-34)
\end{abstract}

Keywords: Peak cough flow, Vital capacity, Dysphagia, Diet, Stroke

\section{INTRODUCTION}

Swallowing is a complex neuromuscular process, regulated by the swallowing center at the brainstem ${ }^{1}$.
Stroke induces abnormal swallowing physiology by reducing lingual control, leading to pharyngeal dyssynergia, or delayed swallowing reflex, which causes pharyngeal pooling ${ }^{2}$. It is estimated that $28-65 \%$ of
Received: April 24 2020, Revised: April 24 2020,

Accepted: May 292020

Corresponding author: Yoon Ghil Park, Department of Rehabilitation Medicine, Gangnam Severance Hospital, Rehabilitation Institute of Neuromuscular Disease, Yonsei University College of Medicine, 211 Eonju-ro, Gangnamgu, Seoul 06273, Korea Tel: +82-2-2019-3493, Fax: +82-2-2019-4807

E-mail:DRTLC@yuhs.ac
Copyrights (c) The Korean Dysphagia Society, 2021. 
post-stroke patients have dysphagia ${ }^{3}$. Moreover, symptoms of aspiration have been reported in $21-51 \%$ of post-stroke patients, with a prevalence of aspiration pneumonia of $18-19 \%$.

Several studies have reported the relationship between dysphagia and pulmonary function, such as the development of pulmonary complications due to dysphagia $^{6}$ and the development of dysphagia in patients with chronic obstructive pulmonary disease $(\mathrm{COPD})^{7,8}$. Furthermore, a difference in peak cough flow (PCF) between stroke patients with and without dysphagia has been observed ${ }^{9}$. Moreover, a significant decrease in vital capacity (VC) and inspiratory reserve volume in post-stroke patients with dysphagia has been reported $^{10}$.

Despite of numerous studies on the relationship between dysphagia and pulmonary function, the mechanism which stage of the swallowing is related to the pulmonary function has not been clarified. Furthermore, less attention has been given to the relationship between pulmonary function and diet level. In this study, we hypothesized that the lower the pulmonary function, the higher the risk of aspiration in post-stroke patients. Additionally, we hypothesized that a lower diet level would correlate to lower pulmonary function in these patients. To support these hypotheses, we assessed the correlation between parameters of a videofluoroscopic dysphagia scale (VDS) and VC or PCF. In addition, it was assessed whether there is a difference in pulmonary function according to the diet level, which was decided by severity of dysphagia.

\section{MATERIALS AND METHODS}

\section{Subjects}

A retrospective analysis was conducted on 102 post-stroke patients who were hospitalized between June 2017 and October 2017 in the Department of Rehabilitation Medicine of a tertiary hospital. Of 102 post-stroke patients, 38 patients met the following inclusion criteria: (1) age $\geq 15$ years; (2) first attack of ischemic or hemorrhagic stroke confirmed by brain magnetic resonance imaging or computed tomography; (3) onset of stroke $\leq 1$ year; (4) cognitive ability to follow the examinations including pulmonary function test; (5) underwent VFSS for swallowing function; and (6) underwent VC and PCF for pulmonary function, as shown in the flowchart.(Fig. 1) Of the 38 patients who met the inclusion criteria, two patients met at least one of the following exclusion criteria: (1) history of previous dysphagia $(n=1)$; (2) history of cardiopulmonary disease, such as thoracotomy, COPD, or pulmonary granuloma $(n=1)$; and (3) history of neuromuscular diseases, such as muscular dystrophy, spinal muscular atrophy, or Guillain-Barre syndrome (n=0).(Fig. 1) Ultimately, 36 post-stroke patients were eligible for the analysis based on the abovementioned criteria. This study was approved by the Institutional Review Board of Gangnam Severance Medical Center (3-2019-0409).

\section{Materials}

Swallowing function was evaluated using the VFSS, and pulmonary function was assessed with VC and PCF. VFSS was evaluated within 1 week after admission, and VC and PCF were measured prior to VFSS. The patients were divided into two groups (aspiration or non-aspiration) according to VFSS results. The diet levels of the patients were compared at admission and discharge. Demographic data, including sex, age, days since onset, location of brain lesion, paralyzed side, and tracheostomy status, were collected. Cognition was assessed using the Korean Mini-Mental Status Examination (K-MMSE), and functional status was assessed by Functional Independence Measure (FIM) at admission. Both cognition and functional status were assessed at admission.

\section{1) Evaluation of dysphagia}

To assess swallowing function, a VFSS was conducted within 1 week after admission. The VFSS was conducted by two experienced physiatrists, who were assisted by one technician. The VFSS diet was prepared as a semisolid, a solid and liquid bolus (5 and $15 \mathrm{ml}$, sequentially) mixed with barium (Solotop Suspension 140). The liquid, semisolid, and solid diets 


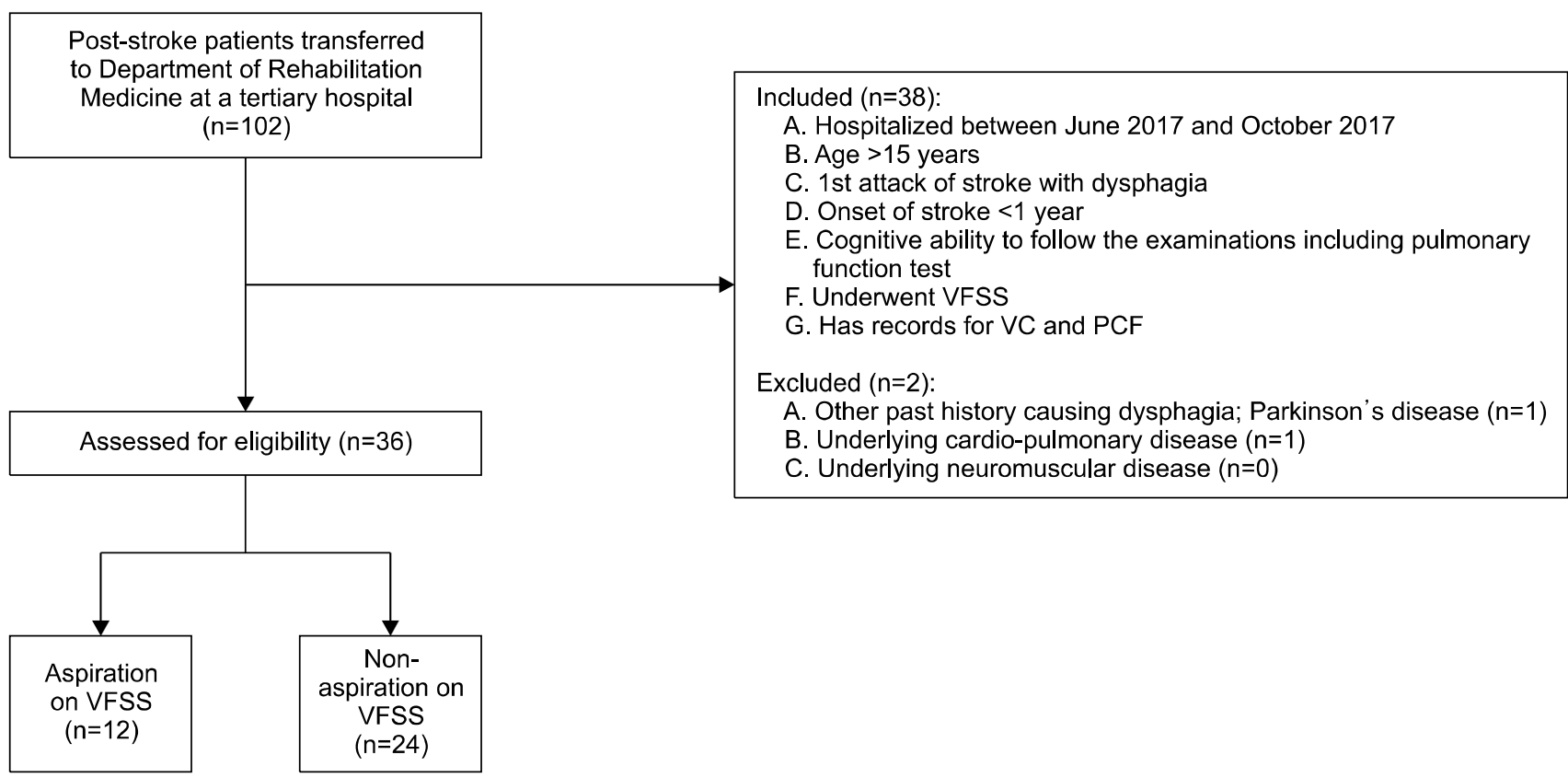

Fig. 1. Flow diagram.

PCF: peak cough flow, VC: vital capacity, VFSS: video-fluoroscopic swallowing study.

corresponded to level 0 (thin drink), 4 (puréed food), and 7 (regular food), respectively, according to the International Dysphagia Diet Standardization Initiative (IDDSI) framework ${ }^{11}$. While in a seated position, patients were fed the abovementioned diets using a spoon or syringe. The results of each VFSS were recorded and encoded into a video file at 30 frames/ sec. An experienced physiatrist reviewed all of the VFSS videos and analyzed them using the PenetrationAspiration Scale (PAS) and the videofluoroscopic dysphagia scale (VDS). The VDS, developed by Han et al. in 2008, has a score range of $0-100^{12}$. A higher score indicates more severe dysphagia.

\section{2) Evaluation of pulmonary function}

Pulmonary function was assessed using VC and PCF. While in a seated position, a patient's nose and lips were fitted into a facial mask to seal the breath, and they were instructed to completely exhale with a constant flow and then to inhale deeply. VC was measured using a portable spirometer (Micro®, Micro Medical Ltd. England), and results were divided by height and age-related prediction value using percentage. To measure PCF, patients were asked to forcefully exhale into a peak flow meter (Assess ${ }^{\circledR}$, Respironics, United States). These measurements were performed by a professional physiatrist who had no relationship with this study, and who performed procedures according to the standards of the American Thoracic Society/European Respiratory Society ${ }^{13}$.

Six patients in this study had a tracheostomy tube. Their pulmonary function was measured with either a spirometer or a peak flow meter, which was connected to the proximal tip of the tracheostomy tube according to the procedure described in Winck et al. ${ }^{14}$. The pulmonary function test was conducted as one of the critical elements of post-stroke evaluation.

\section{3) Classification of diet levels}

Diet levels were divided according to severity of dysphagia using the IDDSI Functional Diet Scale (IDDSI-FDS) $^{15,16}$, consisting of liquid level (not applicable, level 4, 3, 2, 1 according to viscosity) and food level (puréed diet as level 4, minced and moist diet as level 5, soft diet as level 6, and general solid diet as level 7). The combination of each food level and liquid level determines the level of IDDSI-FDS between $0-8$. Patients were divided into three groups 
based on IDDSI-FDS: tube feeding (level 0, limit the oral intake of any diet), dysphagia diet (levels 1-6 : food level 4-6 and liquid level not applicable-1) and general solid diet (level 7,8: food level 7-8 and liquid level 1). Furthermore, the dysphagia diet group was subdivided into 3 groups as follows; level 1 (food level 4 and liquid level not applicable to 4), level 2-3 (food level 4-5 and liquid level 3), level 4-6 (food level 5-6 and liquid level 2-1).

\section{Statistical analysis}

The baseline characteristics of patients were analyzed using a chi-square test for categorical variables (sex, lesions, paralyzed side, tracheostomy status) and a t-test for continuous variables (age, days since onset, FIM, K-MMSE). To determine the risk factors for aspiration, a logistic regression analysis was performed with the following variables: age, sex, lesions, paralyzed side, tracheostomy status, K-MMSE, and pulmonary function (VC, PCF). The cutoff values of VC (\%) and PCF (L/min) to present aspiration on VFSS were obtained using the receiver operating characteristic (ROC) curve. The patients were grouped as above and at or below the cutoff values of $\mathrm{VC}$ and PCF. Intergroup differences of VDS sub-items and total score were analyzed using an independent t-test. Pearson correlation coefficients were calculated between VDS total score and pulmonary function. A one-way analysis of variance (ANOVA) analysis was performed to analyze the significant difference between VC and PCF in the more than three diet groups. Statistical analyses were conducted using SAS version 9.4 (SAS Institute, Cary, NC, United States), and the significance level was set at $\mathrm{P}<0.05$.

\section{RESULTS}

\section{Baseline characteristics}

The characteristics of these groups are shown in Table 1. Using VFSS, 12 patients were in the aspiration group, and 24 patients were in the nonaspiration group. There was no significant difference in general characteristics between the aspiration and non-aspiration groups. A logistic regression analysis showed that only VC was statistically associated with the prevalence of aspiration $(\mathrm{P}=0.03)$.

\section{Optimal cutoff values of VC and PCF for aspiration}

The optimal cutoff point of VC for aspiration on VFSS, acquired from the maximal Youden's index, was $\leq 47.8 \%$ (area under the ROC curve [AUC] $=0.86$ [0.72-0.99], $P<0.05$, sensitivity=1.00 [1.00-1.00], specificity $=0.75[0.59-0.97])$. For PCF, the cutoff point was $\leq 155 \mathrm{~L} / \mathrm{min}$ (AUC=0.73 [0.43-1.00], $\mathrm{P}<0.05$, sensitivity= $0.75[0.5-1.00]$, specificity $=0.69$ [0.25-0.97]).

\section{Difference in VDS sub-items and PAS between the two groups divided by the cutoff value of VC and PCF for aspiration}

Kolmogorov-Smirnov test was performed as a normality test, and VDS total score evaluated liquid and solid showed normality $(\mathrm{P}=0.051, \mathrm{P}=0.052$, respectively). In terms of VDS sub-items, the independent t-test showed intergroup differences in the sub-items of "oral transit time", "triggering of pharyngeal swallow" and "VDS total score" between the two groups according to the cutoff value of VC for aspiration ( $\mathrm{P}<0.01, \mathrm{P}=0.02, \mathrm{P}=0.02$, respectively). There were significant intergroup differences in sub-items of "triggering of pharyngeal swallow", "aspiration", "vallecular residue" and "VDS total score" between the two groups when divided by the cutoff value of PCF for aspiration $(\mathrm{P}=0.01, \mathrm{P}=0.03, \mathrm{P}<0.01, \mathrm{P}=0.01$, respectively).(Table 2) In terms of PAS, the independent t-test showed a significant intergroup difference between the two groups according to the cutoff value of PCF for aspiration, however, no significant difference according to the cutoff value of $\mathrm{VC}(\mathrm{P}<0.01$, $\mathrm{P}=0.46)$. (Table 2)

\section{Relationship between VDS score and VC or PCF}

The VDS score evaluated with liquid showed a weak correlation with $\mathrm{VC}(\mathrm{r}=-0.37, \mathrm{P}=0.03)$. The lower the VDS score with liquid, the higher the VC. 
Table 1. Demographic characteristics of patients.

\begin{tabular}{|c|c|c|c|}
\hline \multirow{2}{*}{ Variables } & Aspiration on VFSS & Non-aspiration on VFSS & \multirow{2}{*}{ P-value } \\
\hline & $12(33.3)$ & $24(66.7)$ & \\
\hline Sex, No. (\%) & & & 0.47 \\
\hline Male & $8(66.7)$ & $13(54.2)$ & \\
\hline Female & $4(33.3)$ & $11(45.8)$ & \\
\hline Age, mean $\pm S D, y$ & $56.75 \pm 19.94$ & $62.54 \pm 16.07$ & 0.39 \\
\hline Period from onset, mean $\pm S D$, day & $110.58 \pm 111.52$ & $86.63 \pm 92.59$ & 0.50 \\
\hline Lesions, No. (\%) & & & 0.12 \\
\hline Supratentorial & $5(41.7)$ & $18(75.0)$ & \\
\hline Infratentorial & $6(50.0)$ & $5(20.8)$ & \\
\hline Supra- and infratentorial & $1(8.3)$ & $1(4.2)$ & \\
\hline Paralyzed side, No. (\%) & & & 0.41 \\
\hline Rt. hemiplegia & $1(8.3)$ & $7(29.2)$ & \\
\hline Lt. hemiplegia & $4(33.3)$ & $5(20.8)$ & \\
\hline Quadriplegia & $7(58.3)$ & $12(50.0)$ & \\
\hline Tracheostomy, No. (\%) & & & 0.38 \\
\hline Tracheostomised & $3(25.0)$ & $3(12.5)$ & \\
\hline Not tracheostomised & $9(75.0)$ & $21(87.5)$ & \\
\hline $\mathrm{K}-\mathrm{MMSE}$, mean $\pm \mathrm{SD}$ & $23.67 \pm 8.62$ & $20.54 \pm 7.16$ & 0.28 \\
\hline FIM, mean \pm SD & $69.00 \pm 35.66$ & $59.13 \pm 24.22$ & 0.33 \\
\hline $\mathrm{VC}$, mean $\pm \mathrm{SD}$ & $50.43 \pm 27.85$ & $61.13 \pm 21.21$ & \\
\hline $\mathrm{PCF}$, mean $\pm \mathrm{SD}$ & $230.83 \pm 148.41$ & $209.17 \pm 98.82$ & \\
\hline VDS total score ${ }^{\dagger}$, mean \pm SD & $30.25 \pm 18.11$ & $12.60 \pm 10.36$ & \\
\hline \multicolumn{4}{|l|}{ Diet level, No. (\%) } \\
\hline Tube feeding & $5(41.7)$ & $2(8.3)$ & \\
\hline Dysphagia diet & $5(41.7)$ & $7(29.2)$ & \\
\hline General diet & $2(16.6)$ & $15(62.5)$ & \\
\hline
\end{tabular}

FIM: functional independence measure, K-MMSE: Korean Mini-Mental Status Examination, VFSS: video-fluoroscopic swallowing study, PCF: peak cough flow, VC: vital capacity, VDS: videofluoroscopic dysphagia scale.

${ }^{+}$VDS total score evaluated with liquid.

However, there was no significant association between VDS score evaluated with solid and VC, and VDS score evaluated with solid or liquid and PCF.

\section{Correlations between the diet level at admission and pulmonary function}

The diet level at admission was statistically correlated with VC $(r=0.57, \mathrm{P}<0.01)$ and weakly with $\mathrm{PCF}$ $(r=0.36, P=0.03)$ by Pearson's correlation. When dividing the patients by the three diet levels at admission, the mean VC showed significant differences among the groups by the one-way ANOVA $(\mathrm{P}<0.01)$. In a post hoc study, VC of the dysphagia diet group $(58.37 \pm 26.83)$ and the general diet group (67.53 \pm 14.88) were higher than that of the tube feeding group $(31.95 \pm 18.43)(P=0.01$ and $P<0.01)$. Additionally, the mean PCF of the three diet groups showed a significant difference $(\mathrm{P}=0.05)$. In a post hoc study, PCF of the general diet group (248.82 \pm 74.49$)$ was higher than that of the tube feeding group (124.29 \pm 77.86) ( $\mathrm{P}=0.02)$. (Fig. 2)

To further refine the division of dietary stages according to swallowing function, the dysphagia diet group was divided into IDDSI-FDS level $1(\mathrm{n}=4)$, level 2-3 ( $n=3)$, level 4-6 ( $n=5)$. The mean VC of the dysphagia diet groups were $35.57 \pm 34.05$ (level 1), 55.78 \pm 26.00 (level 2-3), 64.13 \pm 13.64 (level 4-6). The mean PCF of the dysphagia diet group were $103.33 \pm 35.12$

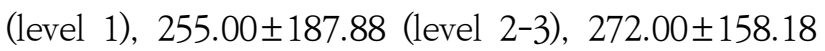
(level 4-6). These mean VC and PCF showed significant differences in the five groups (tube feeding group, three dysphagia diet groups, general diet group) by the one-way ANOVA $(\mathrm{P}<0.01, \mathrm{P}=0.03)$. 
Table 2. VDS and PAS results of the two groups divided by the cutoff values of VC or PCF for aspiration.

\begin{tabular}{|c|c|c|c|c|c|c|}
\hline \multirow[b]{2}{*}{ Variables, No. (\%) } & \multicolumn{3}{|c|}{$\mathrm{VC}$} & \multicolumn{3}{|c|}{ PCF } \\
\hline & $\begin{array}{l}\text { Above cutoff } \\
(>47.8 \%)\end{array}$ & $\begin{array}{c}\text { At or below cutoff } \\
(\leq 47.8 \%)\end{array}$ & P-value & $\begin{array}{l}\text { Above cutoff } \\
(>155 \mathrm{~L} / \mathrm{min})\end{array}$ & $\begin{array}{l}\text { At or below cutoff } \\
(\leq 155 \mathrm{~L} / \mathrm{min})\end{array}$ & P-value \\
\hline Lip closure & $0.00(0.00)$ & $0.17(0.58)$ & 0.16 & $0.00(0.00)$ & $0.15(0.56)$ & 0.19 \\
\hline Bolus formation & $0.13(0.61)$ & $0.50(1.17)$ & 0.21 & $0.13(0.63)$ & $0.46(1.13)$ & 0.26 \\
\hline Mastication & $0.00(0.00)$ & $0.33(1.16)$ & 0.16 & $0.00(0.00)$ & $0.31(1.11)$ & 0.18 \\
\hline Apraxia & $0.13(0.61)$ & $0.25(0.58)$ & 0.56 & $0.20(0.69)$ & $0.12(0.42)$ & 0.71 \\
\hline Tongue to palate contact & $0.21(1.02)$ & $0.83(1.95)$ & 0.21 & $0.22(1.04)$ & $0.77(1.88)$ & 0.26 \\
\hline Premature bolus loss & $1.25(1.44)$ & $2.21(1.44)$ & 0.07 & $1.24(1.48)$ & $2.15(1.39)$ & 0.08 \\
\hline Oral transit time & 0.88 (1.39) & $3.00(0.00)$ & $<0.01^{* *}$ & $1.30(1.52)$ & $2.08(1.44)$ & 0.15 \\
\hline Triggering of pharyngeal swallow & $2.44(2.29)$ & $4.13(1.30)$ & $0.02^{*}$ & $2.34(2.30)$ & $4.15(1.25)$ & $0.01^{*}$ \\
\hline Vallecular residue & $0.83(1.55)$ & $1.17(1.59)$ & 0.37 & $0.70(1.43)$ & $2.31(1.60)$ & $<0.01^{* * *}$ \\
\hline Laryngeal elevation & $0.00(0.00)$ & $0.75(2.60)$ & 0.16 & $0.00(0.00)$ & $0.69(2.50)$ & 0.19 \\
\hline Pyriformis sinus residue & $0.75(2.17)$ & $1.13(2.04)$ & 0.62 & $0.78(2.21)$ & $1.04(1.97)$ & 0.73 \\
\hline Coating of pharyngeal wall & $1.13(3.04)$ & $2.25(4.07)$ & 0.36 & $0.78(2.59)$ & $2.77(4.32)$ & 0.09 \\
\hline Pharyngeal transit time & $0.75(2.03)$ & $1.50(2.71)$ & 0.36 & $0.52(1.73)$ & $1.85(2.88)$ & 0.09 \\
\hline Aspiration & $2.00(4.57)$ & $5.00(6.18)$ & 0.11 & $1.57(4.13)$ & $5.54(6.23)$ & $0.03^{*}$ \\
\hline VDS total score & $10.48(14.03)$ & $24.21(19.24)$ & $0.02 *$ & $9.78(13.81)$ & $24.39(18.58)$ & $0.01^{*}$ \\
\hline PAS & $3.75(2.77)$ & $4.42(2.39)$ & 0.46 & $3.13(2.63)$ & $5.46(1.94)$ & $0.01^{*}$ \\
\hline
\end{tabular}

Values are mean values (standard deviations) of sub-items in VDS scale.

PAS: penetration-aspiration scale, PCF: peak cough flow, VC: vital capacity, VDS: videofluoroscopic dysphagia scale. $* \mathrm{P}<0.05,{ }^{* *} \mathrm{P}<0.01$.

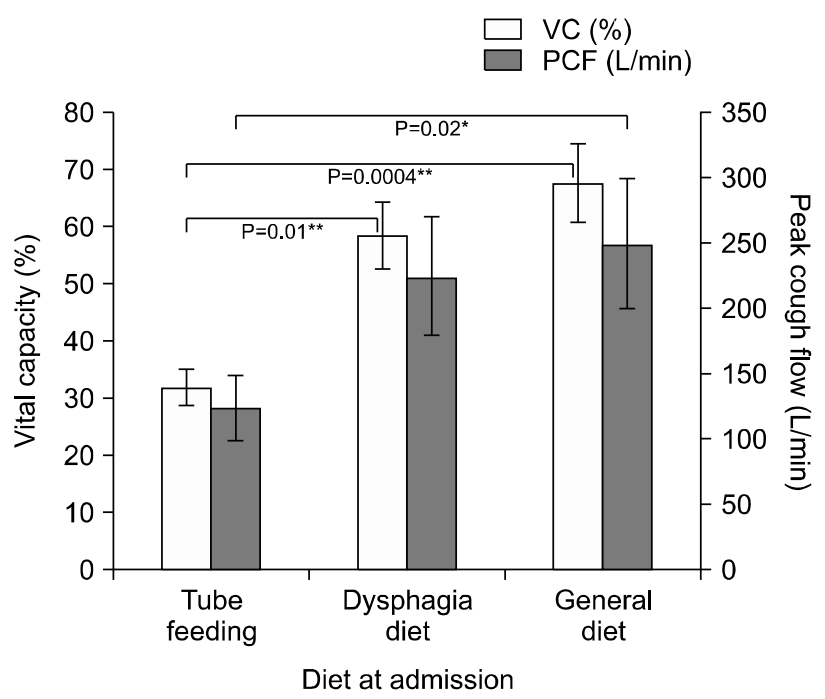

Fig. 2. Pulmonary function among the 3 different diet groups. PCF: peak cough flow, VC: vital capacity.

\section{DISCUSSION}

This study supported the significant correlation between the pulmonary and swallowing function in post-stroke patients. Additionally, in the group of patients with low dietary levels, pulmonary function was further reduced. Previous studies have confirmed that post-stroke patients with aspiration show much lower forced VC than those without aspiration ${ }^{17,18}$. After stroke, weakness of the diaphragm and of the intercostal and abdominal muscles is known to contribute to a decrease in movement of the chest wall, resulting in a decrease of $\mathrm{VC}^{17,19}$. In this study, the optimal cutoff value of $\mathrm{VC}$ to predict aspiration was 47.8\% (AUC=0.86). This result is consistent with those of a previous review of studies, which reported that swallowing initiation occurs between $42 \%$ and $48 \%$ of $\mathrm{VC}$, which is interpreted as a sufficient amount to prevent airway aspiration during swallowing ${ }^{20}$.

Moreover, VC and VDS scores showed negative correlation $(r=-0.37, P=0.03)$. These results imply that the larger the lung volume, the better the swallowing ability. Swallow apnea, or breathing pauses during swallowing, is known to occur to prevent aspiration. It has been reported that when the VC is larger, the duration of swallow apnea becomes longer ${ }^{21}$. When VC is large enough, aspiration occurs less and swallowing becomes better, which is consistent with the results of this study. The specific cutoff value of PCF 
predicting aspiration was $155 \mathrm{~L} / \mathrm{min}$ (AUC=0.73). These results are similar to results reported in a previous study, which showed that the optimal cutoff value of PCF for decannulation in neuromuscular disease was $160 \mathrm{~L} / \mathrm{min}^{22}$. Although it is known that PCF is lower in post-stroke patients with dysphagia, there is a lack of studies confirming the optimal cutoff value of PCF in post-stroke patients. Also, the cutoff value of PCF can be a useful indicator in predicting pulmonary complications, such as aspiration pneumonia, in poststroke patients with dysphagia.

This study also examined whether pulmonary function was related to specific elements of the swallowing process. The result shows that "oral transit time" is longer in cases where VC is lower than $47.8 \%$, and that "aspiration", "vallecular residue" are more found when PCF does not exceed $155 \mathrm{~L} / \mathrm{min}$. Since the oral cavity and pharyngeal space are shared for both swallowing and breathing processes, the $\mathrm{co}^{-}$ ordination between breathing and swallowing is very important for safe swallowing ${ }^{23,24}$. The food bolus is aggregated in the oral cavity before being propelled posteriorly to the pharynx. Then, the swallowing apnea begins approximately synchronously with the initiation of bolus propulsion with liquid ${ }^{25}$, or begins substantially before the swallowing with solid food ${ }^{26,27}$. As the prolonged transited food could not trigger the swallowing reflex at the exact time point of the respiratory cycle, sufficient time would be required for mastication and subsequent swallowing apnea, so that the swallowing apnea can be stopped and the food can be transited at the right time and in a safe way $^{23,28}$. It is thought that a large volume of VC would be beneficial in sufficiently securing this time.

PCF represents how strongly a foreign body can be expelled from the airway by coughing. A previous study demonstrated that the intensity of voluntary cough was correlated with the risk of aspiration pneumonia $^{10}$; the weaker the PCF, the more likely it is that the foreign body will pass through the vocal cord. Several previous studies have reported that the closure of the larynx is an important factor for effective cough $^{29-31}$. These reports support the correlation be- tween the PCF and laryngeal closure revealed in the present study. The consistent result was confirmed in analysis of the VDS scale. "Vallecular residue" and "aspiration" showed significant intergroup differences when patients were divided by the cutoff value of PCF. This result is generally consistent with the results from a previous study, which showed a significant correlation between PCF and pharyngeal residue $^{32}$. As a result of the weakness of the pharyngeal muscle in post-stroke patients, residue in the vallecular pouch or pyriformis sinus could cause aspiration. Based on the above results, it should be emphasized that the amount of vallecular residue and aspiration are related to coughing ability.

"Triggering of pharyngeal swallow", one of the subitems in the VDS scale, showed significant intergroup differences when dividing the patients by cutoff values of VC and PCF. There have been reports that the swallowing reflex affects pulmonary function in COPD patients and causes frequent exacerbations ${ }^{33,34}$. The swallowing reflex is an important factor for directing the oropharyngeal bolus into the esophagus and not into the larynx ${ }^{35}$. Therefore, impairment of this reflex could result in aspiration pneumonia and affect pulmonary function. The result of this study is significant in that few studies have compared the swallowing reflex with pulmonary function in post-stroke patients.

Lastly, this study revealed significant correlations between VC, PCF and diet level, which represented the severity of dysphagia. The volume of VC increases as diet level increases. A few previous studies confirmed significant differences in pulmonary function depending on the presence or absence of dysphagia ${ }^{9,10,36}$. This study differs in that it shows that there is a difference in pulmonary function according to severity of dysphagia in post-stroke patients. In this study, food and liquid were prescribed differently depending on the degree of dysphagia. Liquid levels can be considered in terms of the viscosity of bolus and food levels in terms of the volume of bolus. Several studies have reported that bolus viscosity affects the duration of swallowing apnea ${ }^{20,37,38,39}$. As the 
bolus viscosity become thinner, the bolus velocity become increased. Inamoto $\mathrm{Y}$ et al. confirmed that the closing time of the vocal cord was longer to prevent aspiration when passing a rapid flow bolus into the pharynx ${ }^{40}$. With regard to the extent of hyoid displacement during swallowing, Choi et al. reported that the hyoid excursion, which impacts on airway closure and opening of upper esophageal sphincter, decreased as bolus become thicker ${ }^{41}$. In post-stroke patients with oropharyngeal dysphagia, cricopharyngeal muscle become weak and latency of epiglottic contact become prolonged ${ }^{42}$. It is thought that more pulmonary functions might be required to protect the airway when a thin viscous bolus is swallowed at a rapid rate in these weakened status of post-stroke patients. Also, there were some reports that bolus volume affects the coordination of deglutition and respiration $^{43,44}$. The bolus volume affected the onset of swallowing apnea to become earlier. Early onset of swallowing apnea would lead to the increase in swallowing apnea duration. Adrieen L. et al. also revealed that larger bolus volume needs more longer duration of swallowing apnea in healthy individuals ${ }^{45}$. The decreased ability of chewing is common in post-stroke patients with dysphagia, and if the bolus volume cannot be cut into small enoughly, the duration of swallowing apnea would become longer. However, the weakened pulmonary function identified in these patients will not be able to hold the breath sufficiently, more aspiration would occur. Therefore, it might be necessary to consider the pulmonary function as well as the severity of dysphagia when subscribe the diet level of patients.

The limitation of this study is that we could not shed light on the linear causality between pulmonary function and swallowing function or between pulmonary function and diet level. This is because due to the nature of a retrospective design, we could not adequately adjust for bias. Further, a prior study identified a correlation between MMSE and pulmonary function, and it may be difficult to predict an accurate regression model due to multicollinearity. Additionally, patients who had concomitant diseases, such as aspiration pneumonia and septic shock, or who were medically unstable for conducting the evaluations were excluded. This could have led to a selection bias because severe aspiration cases were not included. Lastly, measuring the pulmonary function of tracheostomy status patients by connecting a spirometer or a peak flow meter to the proximal tip of the tracheostomy tube might underestimate the glottis function and accurately evaluated the PCF. However, most of the patients could not maintain the oxygen saturation while capping the tip of the tracheostomy tube and measuring the pulmonary function through their mouth. The procedure was selected according to Winck et al. ${ }^{14}$. Overall, there is a need for large-scale prospective studies, because the number of patients in this study was small, to correlate pulmonary function with swallowing-related elements and to determine the short and long-term effects of pulmonary rehabilitation on dysphagia.

\section{CONCLUSION}

This study revealed the association between respiratory function and swallowing function in poststroke patients. The higher the risk for airway aspiration was, the lower the VC and PCF were. Further, patients on higher diet levels had better VC and PCF. This suggested that pulmonary function could affect not only swallowing but also the actual diet level. These simple, bedside pulmonary function tests are expected to help prescribe a safe diet in post-stroke patients. Therefore, the clinical importance of pulmonary function test in post-stroke patients with dysphagia should be emphasized.

\section{CONFLICT OF INTEREST}

The authors declare no conflict of interest. There was also no funding for the project. 


\section{REFERENCES}

1. Ertekin C, Aydogdu I. Neurophysiology of swallowing. Clin Neurophysiol 2003;114:2226-44.

2. Abubakar SA, Jamoh BY. Dysphagia following acute stroke and its effect on short-term outcome. Niger Postgrad Med J 2017;24:182-6.

3. Cohen DL, Roffe C, Beavan J, Blackett B, Fairfield CA, Hamdy S, et al. Post-stroke dysphagia: A review and design considerations for future trials. Int J Stroke 2016; 11:399-411.

4. Martino R, Foley N, Bhogal S, Diamant N, Speechley M, Teasell R. Dysphagia after stroke: incidence, diagnosis, and pulmonary complications. Stroke 2005;36:2756-63.

5. Perry L, Love CP. Screening for dysphagia and aspiration in acute stroke: a systematic review. Dysphagia 2001; 16:7-18.

6. PULMONARY complications of dysphagia. Lancet 1953; $1: 688-9$.

7. Tsuzuki A, Kagaya H, Takahashi H, Watanabe T, Shioya T, Sakakibara H, et al. Dysphagia causes exacerbations in individuals with chronic obstructive pulmonary disease. J Am Geriatr Soc 2012;60:1580-2.

8. Park GW, Kim SK, Lee CH, Kim CR, Jeong HJ, Kim DK. Effect of chronic obstructive pulmonary disease on swallowing function in stroke patients. Ann Rehabil Med 2015;39:218-25.

9. Kimura Y, Takahashi M, Wada F, Hachisuka K. Differences in the peak cough flow among stroke patients with and without dysphagia. J uoeh 2013;35:9-16.

10. Min SW, Oh SH, Kim GC, Sim YJ, Kim DK, Jeong HJ. Clinical Importance of Peak Cough Flow in Dysphagia Evaluation of Patients Diagnosed With Ischemic Stroke. Ann Rehabil Med 2018;42:798-803.

11. IDDSI. International dysphagia diet standardization initiative. 2016.

12. Han TR, Paik NJ, Park JW, Kwon BS. The prediction of persistent dysphagia beyond six months after stroke. Dysphagia 2008;23:59-64.

13. Miller MR, Hankinson J, Brusasco V, Burgos F, Casaburi R, Coates A, et al. Standardisation of spirometry. Eur Respir J 2005;26:319-38.

14. Winck J, LeBlanc C, Soto J, Plano F. The value of cough peak flow measurements in the assessment of extubation or decannulation readiness. Revista Portuguesa de Pneumologia (English Edition) 2015;21:94-8.

15. Cichero JA, Lam P, Steele CM, Hanson B, Chen J, Dantas $\mathrm{RO}$, et al. Development of international terminology and definitions for texture-modified foods and thickened fluids used in dysphagia management: the IDDSI framework. Dysphagia 2017;32:293-314.

16. Steele CM, Namasivayam-MacDonald AM, Guida BT, Cichero JA, Duivestein J, Hanson B, et al. Creation and initial validation of the international dysphagia diet standardisation initiative functional diet scale. Archives of physical medicine and rehabilitation 2018;99:934-44.

17. Lanini B, Bianchi R, Romagnoli I, Coli C, Binazzi B, Gigliotti $\mathrm{F}$, et al. Chest wall kinematics in patients with hemiplegia. Am J Respir Crit Care Med 2003;168:109-13.

18. Lima IN, Fregonezi GA, Melo R, Cabral EE, Aliverti A, Campos TF, et al. Acute effects of volume-oriented incentive spirometry on chest wall volumes in patients after a stroke. Respir Care 2014;59:1101-7.

19. Khedr EM, El Shinawy O, Khedr T, Aziz Ali YA, Awad EM. Assessment of corticodiaphragmatic pathway and pulmonary function in acute ischemic stroke patients. Eur J Neurol 2000;7:323-30.

20. McFarland DH, Martin-Harris B, Fortin AJ, Humphries K, Hill E, Armeson K. Respiratory-swallowing coordination in normal subjects: lung volume at swallowing initiation. Respir Physiol Neurobiol 2016;234:89-96.

21. Park YK. Correlation bewteen respiratory function and dysphagia in stroke patients. Journal of the Korean Dysphagia Society 2014;4:23 7-7.

22. Bach JR. Indications for tracheostomy and decannulation of tracheostomized ventilator users. Monaldi Arch Chest Dis 1995;50:223-7.

23. Matsuo K, Palmer JB. Coordination of Mastication, Swallowing and Breathing. Jpn Dent Sci Rev 2009;45:31-40.

24. Matsuo K, Palmer JB. Anatomy and physiology of feeding and swallowing: normal and abnormal. Phys Med Rehabil Clin N Am 2008;19:691-707, vii.

25. Martin-Harris B, Brodsky MB, Michel Y, Ford CL, Walters B, Heffner J. Breathing and swallowing dynamics across the adult lifespan. Arch Otolaryngol Head Neck Surg 2005;131:762-70.

26. Matsuo K, Hiiemae KM, Gonzalez-Fernandez M, Palmer JB. Respiration during feeding on solid food: alterations in breathing during mastication, pharyngeal bolus aggregation, and swallowing. J Appl Physiol (1985) 2008; 104:674-81.

27. McFarland DH, Lund JP. Modification of mastication and respiration during swallowing in the adult human. J Neurophysiol 1995;74:1509-17.

28. Tangel DJ, Mezzanotte WS, White DP. Respiratory-related control of palatoglossus and levator palatini muscle activity. J Appl Physiol (1985) 1995;78:680-8.

29. Britton D, Yorkston KM, Eadie T, Stepp CE, Ciol MA, Baylor C, et al. Endoscopic assessment of vocal fold movements during cough. Ann Otol Rhinol Laryngol 2012;121: 21-7.

30. Hull JH, Backer V, Gibson PG, Fowler SJ. Laryngeal Dysfunction: Assessment and Management for the Clinician. Am J Respir Crit Care Med 2016;194:1062-72.

31. Sandhu GS, Kuchai R. The larynx in cough. Cough 2013; 9:16.

32. Lee SJ, Lee KW, Kim SB, Lee JH, Park MK. Voluntary cough and swallowing function characteristics of acute stroke patients based on lesion type. Archives of physical medicine and rehabilitation 2015;96:1866-72.

33. Terada K, Muro S, Ohara T, Kudo M, Ogawa E, Hoshino 
Y, et al. Abnormal wallowing reflex and COPD exacerbations. Chest 2010;137:326-32.

34. Gross RD, Atwood Jr CW, Ross SB, Olszewski JW, Eichhorn KA. The coordination of breathing and swallowing in chronic obstructive pulmonary disease. American Journal of Respiratory and Critical Care Medicine 2009; 179:559-65.

35. Nishino T. The swallowing reflex and its significance as an airway defensive reflex. Frontiers in physiology 2013; 3:489.

36. Xiao L, Guo Q, Huang F, Liao M, Zhang L, Yan T. Correlation between swallowing function and pulmonary ventilation function and respiratory muscles strength in patients with dysphagia after stroke. Zhonghua yi xue za zhi 2020;100:504-8.

37. Hiss SG, Strauss M, Treole K, Stuart A, Boutilier S. Effects of age, gender, bolus volume, bolus viscosity, and gustation on swallowing apnea onset relative to lingual bolus propulsion onset in normal adults. J Speech Lang Hear Res 2004;47:572-83.

38. Clave P, de Kraa M, Arreola V, Girvent M, Farre R, Palomera E, et al. The effect of bolus viscosity on swallowing function in neurogenic dysphagia. Aliment Pharmacol Ther 2006;24:1385-94.

39. Newman R, Vilardell N, Clavé P, Speyer R. Effect of bolus viscosity on the safety and efficacy of swallowing and the kinematics of the swallow response in patients with oropharyngeal dysphagia: white paper by the European Society for Swallowing Disorders (ESSD). Springer; 2016.

40. Inamoto Y, Saitoh E, Okada S, Kagaya H, Shibata S, Ota $\mathrm{K}$, et al. The effect of bolus viscosity on laryngeal closure in swallowing: kinematic analysis using 320-row area detector CT. Dysphagia 2013;28:33-42.

41. Choi KH, Ryu JS, Kim MY, Kang JY, Yoo SD. Kinematic analysis of dysphagia: significant parameters of aspiration related to bolus viscosity. Dysphagia 2011;26:392-8.

42. Steele CM, Molfenter SM, Péladeau-Pigeon M, Polacco RC, Yee C. Variations in tongue-palate swallowing pressures when swallowing xanthan gum-thickened liquids. Dysphagia 2014;29:678-84.

43. Preiksaitis H, Mayrand S, Robins K, Diamant N. Coordination of respiration and swallowing: effect of bolus volume in normal adults. American Journal of PhysiologyRegulatory, Integrative and Comparative Physiology 1992; 263:R624-R30.

44. Hiss SG, Strauss M, Treole K, Stuart A, Boutilier S. Effects of age, gender, bolus volume, bolus viscosity, and gustation on swallowing apnea onset relative to lingual bolus propulsion onset in normal adults. Journal of Speech, Language, and Hearing Research 2004.

45. Perlman AL, Ettema SL, Barkmeier J. Respiratory and acoustic signals associated with bolus passage during swallowing. Dysphagia 2000;15:89-94. 